\title{
Campaign launched for menopause-friendly dental workplaces
}

A campaign has been established to coincide with Menopause Awareness Month (October) to ensure that all NHS dental services have a menopause policy in place. Joseph Bell (pictured), who has just finished his dental core training, wants to see more menopausefriendly workplaces.

With the backing of his colleague, Professor Claire Stevens, Joseph is setting out to eradicate the taboo that surrounds the menopause across dentistry. The idea for a campaign was born, Joseph explained, after a discussion on clinic about the menopause. Female colleagues shared their experience of menopausal symptoms, some suffering prematurely with fatigue, low mood, heavy bleeding, forgetfulness and hot flushes.

As the topic is openly discussed at his own family home (his mother helped to introduce a menopause policy in her workplace at HSBC bank), Joseph had no inhibitions about being part of the discussion. He said: 'I realised the subject was not usually talked about and that by opening discussions we could help to make big changes for the better and eradicate the taboo surrounding the $\mathrm{M}$ word.

Not only are $76.9 \%$ of the dental team female, ${ }^{1} 35 \%$ of dental care professionals (DCPs) and $43 \%$ of dentists are currently within the age range affected by menopause, ${ }^{2}$ meaning that a significant proportion of the dental workforce is going to be affected by the menopause.

Aspects of work which women cite as making menopause symptoms worse are overheated rooms, poor ventilation, humidity, no access to a quiet or restful space and noise. Long hours, short and changing deadlines, high workloads and dealing with patients can also make symptoms worse.

Joseph said: 'With a high proportion of the dental workforce being female it is imperative we have a good understanding of what we can do to help. He added that he hopes to see training to create workplace environments where women feel comfortable talking to managers or principals about any health-related issues.

Professor Stevens added: 'I was so impressed to see the way Joseph launched his campaign here in Manchester. It's possible that in the future employment law will be changed so that there is protection for women during the menopause - but Joe will have put dentistry ahead of the curve'.

\section{References}

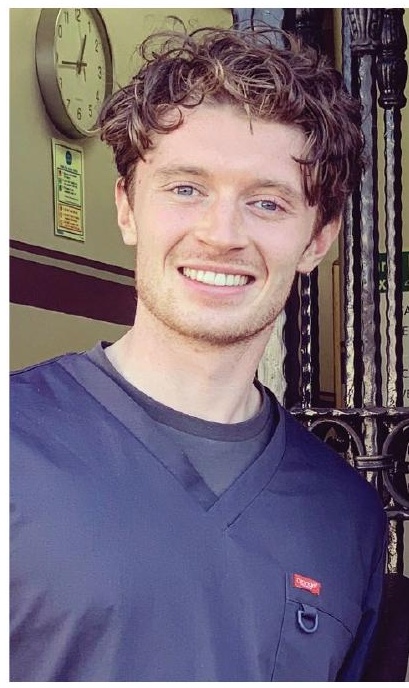

Joseph Bell

1. General Dental Council. Registration Statistical Report 2020. August 2021. Available at: https://www.gdc-uk.org/docs/default-source/registration-reports/gdcregistration-statistical-report-2020---final311fef86-9e9f-44bb-81d8-68b3a44cae39. pdf?sfvrsn=918f77ec_5 (accessed August 2021).

2. General Dental Council. Registration statistical report 2019. October 2020. Available at: https://www.gdc-uk.org/docs/default-source/registration-reports/gdcregistration-statistical-report-2019---final-30-09-2020.pdf?sfvrsn=53215636_12 (accessed August 2021).

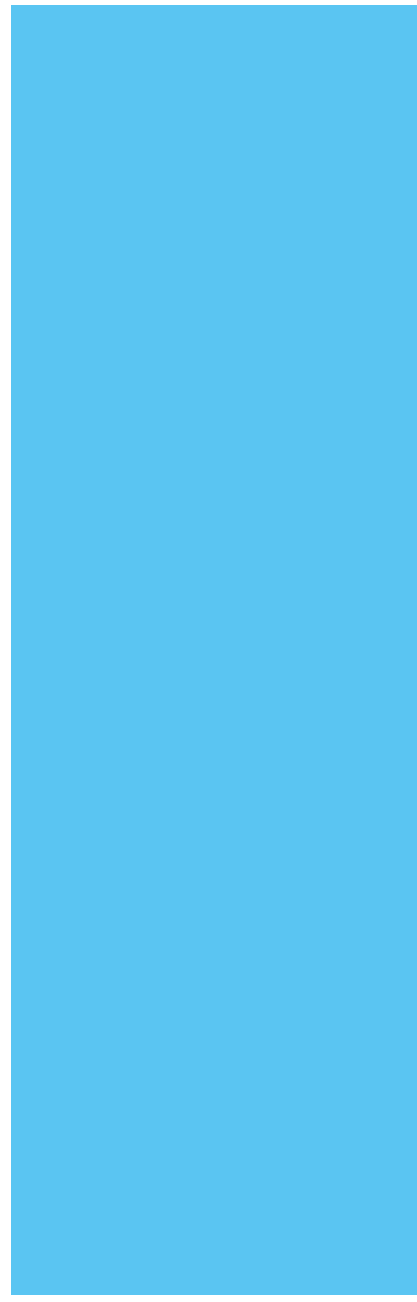

